\title{
Editorial: Authorships and acknowledgements
}

Not long ago we published a single case report emanating from five authors at two hospitalscall them A and B. The first-named author was from B, and not long after publication a letter arrived from a pathologist at $\mathrm{A}$; he pointed out that much of the early history and investigation had been omitted, as had details of treatment received before (and possibly affecting) the main diagnostic investigations at $\mathrm{B}$, which were the subject of the report. Furthermore the physician-author at $\mathrm{A}$ had never seen the manuscript, his name was misspelled, and the hospital was wrongly named.

Such a story shows discourtesy at the least and undermines confidence in the truth of the rest of the report. The plaintiff did not wish to publish his complaints but the editor is disturbed to think that similar events may be not infrequent. We and other journals currently insist that all authors should denote their approval of the manuscript by their signatures, but that does not answer the whole question. Professor Grist writes:

An AUTHOR is, in general, 'the person who originates or gives existence to anything'; especially 'one who sets forth written statements; the writer or composer of a treatise or book' (Oxford English Dictionary, 1933). Most modern medical and scientific writings result from teamwork and result in multiple authorship-although this can sometimes be grossly and ludicrously overdone. It has been recommended that 'the by-line should contain the names of those who have contributed materially to the work and its report; those who have participated only in an advisory or supporting capacity should be thanked in the acknowledgements' (De Bakey, 1977). These words are carefully chosen; authors should have contributed materially both to the work and to its report, the second point being helpfully significant-authors should at least be in a position to stand by every statement in the report, must have approved the text, and must accept responsibility for the whole as well as for any section with which they are specially concerned. Observance of this point would surely curtail some cumbersome lists of co-authors!

Acknowledgements may represent a courtesy, although preferably for more than routine work by remunerated staff. They convey much more than a polite gesture, and it has been suggested that 'the author submitting an article should state ... that the content and wording of acknowledgement of help . . . or criticism has been approved by those whose help is acknowledged' (De Bakey, 1977), since a colleague so thanked may object to the possibility of being thereby regarded as approving of the article of which he is not the author and with which he may be in disagreement. Nevertheless, it is important that evidence and methods be unambiguously specified in scientific articles, if not in full then by citing the authority. For instance, it may not be essential to describe the routine procedure used for haemoglobin estimation cited in a case report, but if the case is one of a new haemoglobinopathy then the haematological evidence must be specified or the authority given, for example, in which laboratory, or by whom, were these tests done-some key point essential to the critical reader, although not necessarily obvious to the author, may depend on this. Perhaps our clinical colleagues more often take their laboratory colleagues thus for granted than vice versabut similar considerations apply in reverse; it is essential that complete evidence is presented or at least is readily traceable. The acceptably worded acknowledgement provides not only for recognition of those who have made more than an ordinary contribution to the work but also for specifying colleagues responsible for providing key evidence, without saddling them with the responsibilities of authorship or the onus of endorsing the thesis.

\section{Reference}

De Bakey, L. (1977). The Scientific Journal: Editorial Policies and Practices. C. V. Mosby, St Louis. 